\title{
Multi-layer Laser Mirrors for Optical Sensors Deposited by Electron Beam Deposition and Ion Assisted Electron Beam Deposition
}

\author{
Laxminarayana Gangalakurti, K Venugopal Reddy, I M Chhabra
}

\begin{abstract}
High reflectivity and low loss mirrors are very much essential for state-of art sensors like Ring Laser Gyroscopes widely used for navigation of moving platforms. Surface scattering is the main source of loss for the Laser mirrors of high reflectivity. Surface scattering also lead to coupling of back reflected light leading to dead band of optical sensors at low input rotation. Super polished glass substrates have been prepared from low expansion glass ceramic material. Surface roughness is achieved about $3-5 \AA$ (RMS value) for the ceramic glass substrates prior to thin film coating. The substrates are deposited with 41 alternative layers of $\mathrm{SiO}_{2}$ and $\mathrm{Ta}_{2} \mathrm{O}_{5}$ of Quarter-Wave optical thickness with Electron Beam Deposition (EBD) technique. Ion beam Assisted Electron Beam Deposition (IAEBD) is used for another batch of substrates to coat identical stack of layers on glass substrates of the same surface quality. The key process parameters of both the coating processes are presented. The optical constants of the films are evaluated with spectroscopic Ellipsometer from $400 \mathrm{~nm}$ to $1600 \mathrm{~nm}$. Total Integrated Scattering is estimated from the achieved surface finishing of mirrors deposited. The multi-layer coatings are characterized with UV-Vis-IR Spectrophotometer and Cavity Ring Down(CRD) loss meter. The quantitative optical loss of the mirrors is measured at $45^{\circ}$ angle of incidence with CRD loss meter. The merits of ion assisted $E B$ process over simple EB coating processes are evaluated against optical constants of thin films and performances of mirrors. Fitness of the processes for realizing Laser mirrors for optical sensors at $632.8 \mathrm{~nm}$ is evaluated.
\end{abstract}

Keywords : Ring Laser, Electron Beam deposition, Ion Assisted Electron Beam deposition, surface roughness, reflectivity, extinction coefficient, cavity ring down loss meter, Tatntalum pentoxide, silicon dioxide.

\section{INTRODUCTION}

$\mathrm{H}_{\text {igh reflectivity thin films have several applications in }}$ optical metrology instruments and electro-optic devices like Ring Laser Gyroscopes and Gravity Sensors. Ring Laser Gyroscopes (RLG) are rotational sensors for strap down navigation for ships, submarines and moving platforms. Rotational sensors where a rate bias stability requires better

Manuscript received on January 09, 2021.

Revised Manuscript received on January 15, 2021.

Manuscript published on February 28, 2021

* Correspondence Author

Laxminarayana Gangalakurti*, Research Centre Imarat, Hyderabad, Telangana, India. Email: g.Inarayaa@rcilab.in

K Venugopal Reddy, Department of Physics, National Institute of Technology, Warangal, Telangana, India. Email: kvr@nitw.ac.in

I M Chhabra, Research Centre Imarat, Hyderabad, Telangana, India. Email: imchhabra@rcilab.in

(C) The Authors. Published by Blue Eyes Intelligence Engineering and Sciences Publication (BEIESP). This is an open access article under the CC BY-NC-ND license (http://creativecommons.org/licenses/by-nc-nd/4.0/) than $0.1^{\circ} / \mathrm{hr}$ engages RLG for its quick start and non-moving parts in the sensor assembly. RLGs require mirrors of reflectivity more than $99.9 \%$. High reflectivity values of the order of $99.9 \%$ or better can be achieved with dielectric multi-layer coating. Multi layer dielectric thin films are deposited with alternatively high and low refractive index materials of a quarter wave thickness of the central wavelength of interest. Generally, $\mathrm{SiO}_{2}$ is chosen as low refractive index material while $\mathrm{Ta}_{2} \mathrm{O}_{5}$ or $\mathrm{TiO}_{2}$ as high refractive index material ${ }^{1}$. Hafnium oxide is also a potential candidate with high refractive index for use in the UV spectral range and with low absorption ${ }^{2}$. For the applications of Laser resonators, surface scattering should be minimum possible and should be with a very low surface roughness value. Roughness of the surface is the measure of vertical deviations from a reference surface. Roughness value depends on the type of polishing techniques adopted to achieve the polished surfaces prior to thin film coating. The process of thin film coating controls the film properties like film adhesion, surface roughness, reflectivity, optical constants, etc.

In this work, thin film coating is carried out in two different techniques on the same quality of substrates, and the quantitative measurement is carried out for the roughness of the surface. Roughness values achieved in the two processes namely EBD and IAEBD technique are contemplated for the Total Integrated Scattering (TIS), which is an important parameter for the application of mirror surfaces for the application of Laser resonators ${ }^{3,4}$. These techniques have been found to be very useful for fabricating Laser mirrors with $\mathrm{TiO}_{2}$ and $\mathrm{SiO}_{2}$ alternatively ${ }^{5}$. The present work brings out the merits of coating techniques correlating, optical constants, reflectivity, total loss and TIS values.

\section{EXPERIMENTAL WORK}

\section{A. Electron Beam Deposition}

Electron Beam Deposition is a form of physical vapour deposition in which target material is bombarded with an energetic electron beam. Electrons are typically generated by a thermionic source or by cold electron emitter, which acts as cathode. The electrons are streamed out of the cathode and directed towards target material placed in a crucible. A pressure less than $0.01 \mathrm{~Pa}$ is generally maintained so that one can take advantage of the long electron mean free path inside the vacuum chamber ${ }^{6}$.

Blue Eyes Intelligence Engineering and Sciences Publication 
A schematic of evaporation of target material placed in a crucible with an electron beam is depicted in Fig. 1.

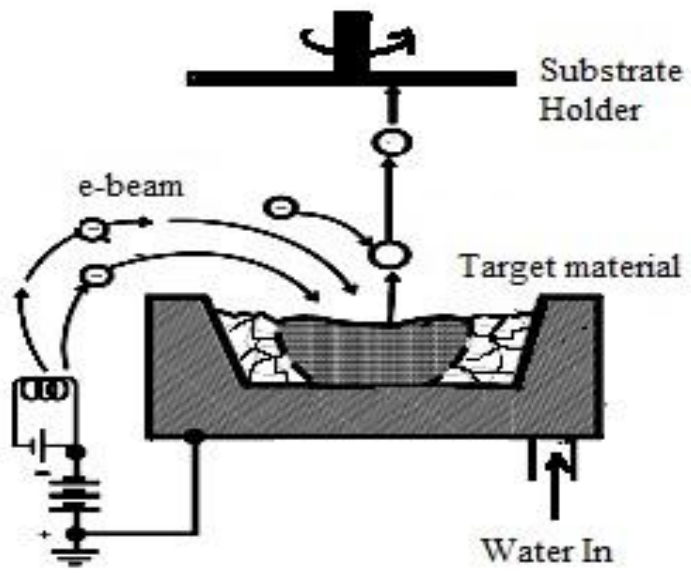

Fig. 1: Schematic of Electron Beam Deposition

In an EBD system, the deposition chamber is to be evacuated to a vacuum of at least $7.5 \times 10^{-5}$ Torr to allow passage of electrons from the electron gun to the evaporation material. Vacuum in the chamber is maintained with a combination of a diffusion pump (pumping speed is around $1700 \mathrm{ltr} / \mathrm{sec}$ ) and a rotary pump (pumping speed is around 40 $\mathrm{m}^{3} / \mathrm{hr}$ ). In the present work, two materials, $\mathrm{Ta}_{2} \mathrm{O}_{5}$ and $\mathrm{SiO}_{2}$ in powder form of grain size around 1 to $3 \mathrm{~mm}$ in separate crucibles are used as high and low refractive index materials respectively. Target material of purity more than $99.99 \%$ is utilized in the present work. The electron beam gun is equipped with four crucibles made of Molybdenum. Electron beam emitted by Tungsten filament of the gun is further accelerated to a high kinetic energy and directed towards the material to be evaporated. The e-beam leaving the cathode is bent about 270 degree by the internal permanent magnet due to which the life of the filament increases. Upon striking the evaporation material, the electrons lose their energy very rapidly. The thermal energy generated in turn melts or sublimates the target material ${ }^{6}$. Accelerating voltages of electron beam can be between $4 \mathrm{kV}-10 \mathrm{kV}$. The filament voltages are 0-12 VAC with maximum current rating of $70 \mathrm{~A}$.

Amplitude and frequency of the beam pattern in the crucible is adjusted with electromagnets. Both the crucible and the gun are cooled continuously with circulation of cooled water with isolation from the chamber. Super polished glass plates are assembled on the substrate holder and fixed on to rotating plate. The substrates are heated in the vacuum chamber up to $200^{\circ} \mathrm{C}$ to desorb the moisture layer from the substrates. Prior to deposition, the substrates are cleaned with discharge plasma. Bombardment of ions and electrons to clean the surface has been commonly used for many years, primarily employing glow discharge in the deposition system $^{7}$. Ionic plasma is created inside the chamber with an Aluminum High Tension (HT) terminal at the power levels of $3.5 \mathrm{~kW}$ at current $500 \mathrm{~mA}$. Dry Argon gas is purged continuously inside the chamber and vacuum is maintained of the order of $10^{-1}$ to $10^{-2}$ Torr. The plasma which contains Ar ions bombards with the substrates and etch the substrates. Substrate cleaning prior to deposition is extremely important for proper film adhesion ${ }^{7}$. The voltages to the HT terminal can be adjusted to give maximum plasma plume at a given

purging rate of Argon gas. The extent of plume can be viewed through glass windows of the chamber while adjusting the voltages. The plasma cleaning continued for about 10-15 minutes prior to thin film deposition.

Thickness of the films is monitored with a quartz crystal oscillator which has a resolution of $0.01 \mathrm{~A}^{\circ}$. Quartz thickness monitor has been calibrated so as to minimize the errors associated with the location of the substrates and the quartz crystal. Evaporation rate is maintained around 1 Angstrom per second. The substrates are deposited with $\mathrm{Ta}_{2} \mathrm{O}_{5}$ and $\mathrm{SiO}_{2}$ materials alternatively of quarter wave thickness at $632.8 \mathrm{~nm}$ as per the stack formula mentioned below: i.e,

Substrate $<[\mathrm{HL}]^{20} \mathrm{H}>$ Air

here, $\mathrm{H}$ indicates High refractive material i.e, $\mathrm{Ta}_{2} \mathrm{O}_{5}$, while $\mathrm{L}$ indicates the Low refractive index material i.e, $\mathrm{SiO}_{2}$. The refractive index considered for calculation of quarter wave thickness of $\mathrm{SiO}_{2}$ at $632.8 \mathrm{~nm}$ is 1.457 for which the thickness of each layer is $108.57 \mathrm{~nm}^{8}$. For $\mathrm{Ta}_{2} \mathrm{O}_{5}$, the refractive index is 2.1203 at $632.8 \mathrm{~nm}$, for which the quarter wave thickness is $74.6 \mathrm{~nm}^{9}$. Chamber is vented with dry nitrogen for collecting the coated samples.

\section{B. Ion Assisted Electron Beam Deposition}

In ion beam assisted electron beam deposition, coating material is evaporated with electron beam and ion beam is projected onto the substrates. The concurrent ion bombardment process differentiates it from other thin film deposition techniques, with an increased kinetic energy of the adatoms resulting increased surface mobility ${ }^{9}$. It is well established that ion beam cleaning significantly improves adhesion and permits control over film properties such as morphology, density, stress level, crystallinity and chemical composition $^{10}$. Arrangement of IAEBD is depicted in Fig. 2.

The work carried out by Commandre and Pelletier for the study of optical properties of $\mathrm{TiO}_{2}$ films by using different processes, indicated that $\mathrm{TiO}_{2}$ films deposited by the energetic processes are more stable than electron-beam (EB) films ${ }^{11}$. Vemuri S Praveen Kumar et al demonstrated angle dependent graded index films of $\mathrm{SiO}_{2}$ from for deposition ${ }^{12}$ angles from $10^{\circ}$ to $80^{\circ}$. In the present work, vapour plume is allowed to incidence at 45 degree of incidence covering thickness monitor at the centre of the substrate rotor.

A set of super polished ceramic glass substrates are placed in the vacuum chamber to have multi-layer coating with the Ion Assisted coating process. Before proceeding to thin film deposition, the substrates are heated to a temperature of $150^{\circ} \mathrm{C}$. Marco Alvisi et al. carried out 5 minutes pre cleaning prior to deposition with ion beam of $\mathrm{Ar}-\mathrm{O}_{2}$ mixture, which resulted higher dame threshold and improved film adhesion to substrate $^{13}$. Jian Leng et al reported Ge film deposition on $\mathrm{ZnS} \& \mathrm{Bk} 7$ substrates where the substrate surfaces were pre-cleaned using Ar ion bombardment for 5 minutes in order to further reduce contamination on the substrate surfaces ${ }^{14}$.

Published By:

Blue Eyes Intelligence Engineering and Sciences Publication

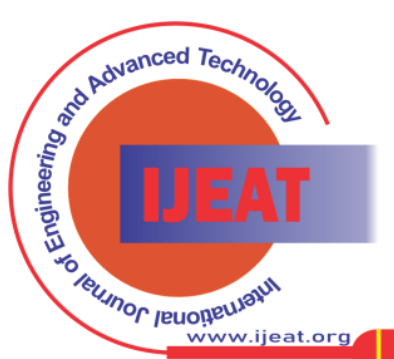




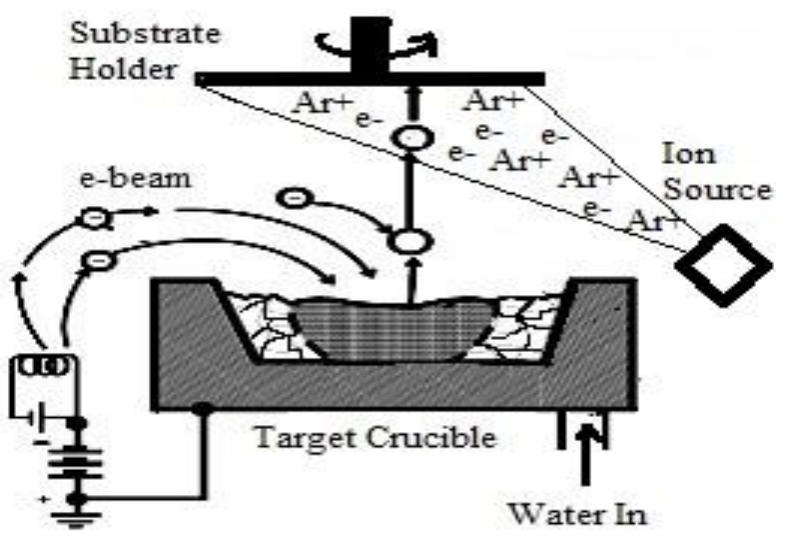

Fig. 2: Schematic of Ion Assisted Electron Beam Deposition.

It is also reported that transmittance peak of the sample prepared without ion-beam bombardment is less than the sample prepared with $150 \mathrm{eV}$ ion energy. The substrates in the present work also were cleaned with ion beam for 5 minutes at a stretch. A grid-less end hall ion source is engaged for generating divergent ion beam on to the substrates. Commandre et al. varied ion beam energy up to $1500 \mathrm{eV}$ for deposition of $\mathrm{TiO}_{2}$ in ion assisted EB coating method and it was observed that the refractive index is maximum when ion beam energy is operated at $300-400 \mathrm{eV}^{11}$. In ion-assisted deposition of $\mathrm{SiO}_{2}$ and $\mathrm{TiO}_{2}$, when the ion beam energy is more than $500 \mathrm{eV}$, assist beam damages the film and produces other effects also ${ }^{15}$. For $\mathrm{SiO}_{2}, \mathrm{Ta}_{2} \mathrm{O}_{5}$ films deposition in the present work, the ion source is operated with ion beam energy in the range $300-400 \mathrm{eV}$. The amount and type of ion bombardment greatly influence film structure and composition. This, in turn, also affects optical, mechanical and electrical properties of the film ${ }^{16}$. A partial pressure of around $2 \times 10^{-4}$ mbar to $4 \times 10^{-4}$ mbar is maintained inside the chamber with oxygen gas flow to facilitate better stoichiometry of the films during deposition. The substrates are deposited with 41 layers of $\mathrm{Ta}_{2} \mathrm{O}_{5}$ and $\mathrm{SiO}_{2}$ materials alternatively by ion assisted electron beam evaporation process. Throughout the deposition process, the substrates are continuously shone with the assist ion source. In both the deposition processes, the substrates are deposited with the same optical thin film design and stack formula.

\section{CHARACTERIZATION OF THIN FILMS}

\section{A.Surface Roughness of Thin Films}

Surface quality of the bare substrates and the coated surfaces are measured with non-contact Veeco optical surface profiler which has an accuracy of $1 \mathrm{~A}^{0}$. This equipment works on the principle of Phase Shifting Interferometry (PSI). In Phase-Shifting Interferometry, a white light beam is filtered and passed on to a test optical surface. The interferometer beam splitter reflects half of the incident beam to the reference surface within the interferometer ${ }^{10}$. Interference fringes are formed on combining waves from test surface and reference optical surface. The reference wave front is moved along the direction of propagation with respect to the wave front being analyzed, thus changing the phase differences ${ }^{17}$. Surface roughness of the bare substrates of each batch prior to deposition is recorded with surface profilometer and 2D
Fig. 3: 2D Surface Profile of Bare Substrate

The multi-layer coatings are evaluated for surface roughness with optical profilometer. The average roughness and rms roughness of the films are $0.85 \mathrm{~nm}$ and $1.76 \mathrm{~nm}$ respectively with EBD technique. 2D profile of films with EBD and IAEBD mirrors are shown in Fig. 4 and Fig.5 respectively. IAEBD mirrors exhibited an average and rms roughness of $0.36 \mathrm{~nm}$ and $0.46 \mathrm{~nm}$ respectively. Roughness parameters such as average roughness value $R_{a}$, RMS roughness value $R_{q}, 10$ point average of peak-valley roughness $R_{z}$, highest peak-lowest valley point roughness $R_{t}$ are measured and are tabulated in Table-I.

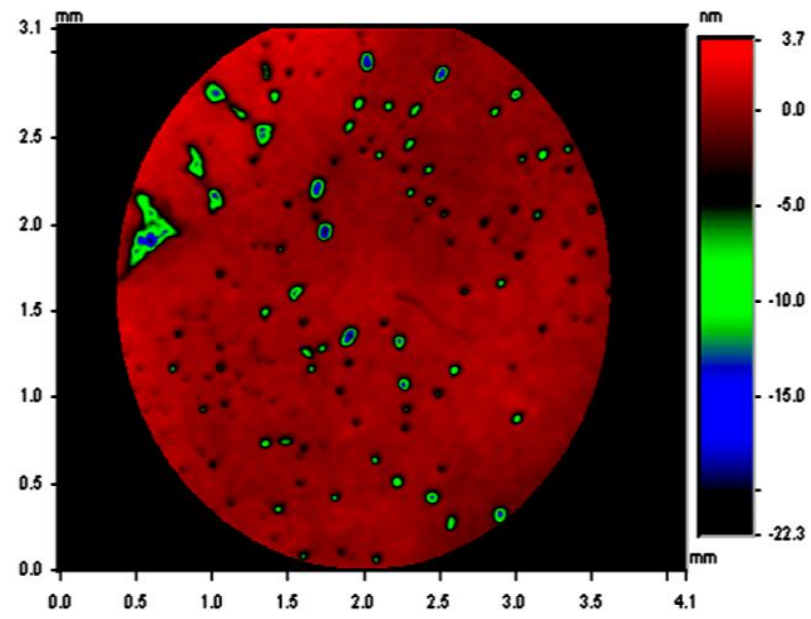

Fig. 4: Surface Profile of EBD Laser Mirror

Table-I: Surface Roughness of Bare Substrate, EBD and IAEBD Films

\begin{tabular}{cccc}
\hline \hline $\begin{array}{c}\text { Roughness } \\
\text { parameter }\end{array}$ & $\begin{array}{c}\text { Bare } \\
\text { substrate }\end{array}$ & $\begin{array}{c}\text { EBD } \\
\text { Film }\end{array}$ & $\begin{array}{c}\text { IAEBD } \\
\text { Film }\end{array}$ \\
\hline $\mathrm{R}_{\mathrm{a}}(\mathrm{nm})$ & 0.27 & 0.85 & 0.36 \\
$\mathrm{R}_{\mathrm{q}}(\mathrm{nm})$ & 0.34 & 1.76 & 0.46 \\
$\mathrm{R}_{\mathrm{z}}(\mathrm{nm})$ & 2.82 & 21.80 & 4.61 \\
$\mathrm{R}_{\mathrm{t}}(\mathrm{nm})$ & 3.31 & 26.06 & 11.17 \\
\hline \hline
\end{tabular}

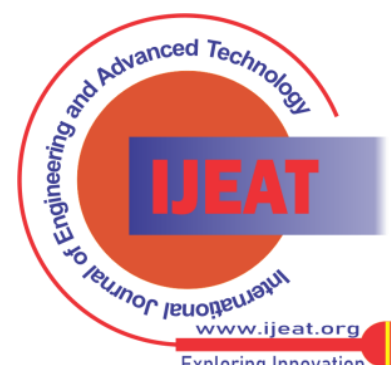

Exploring Innovation 


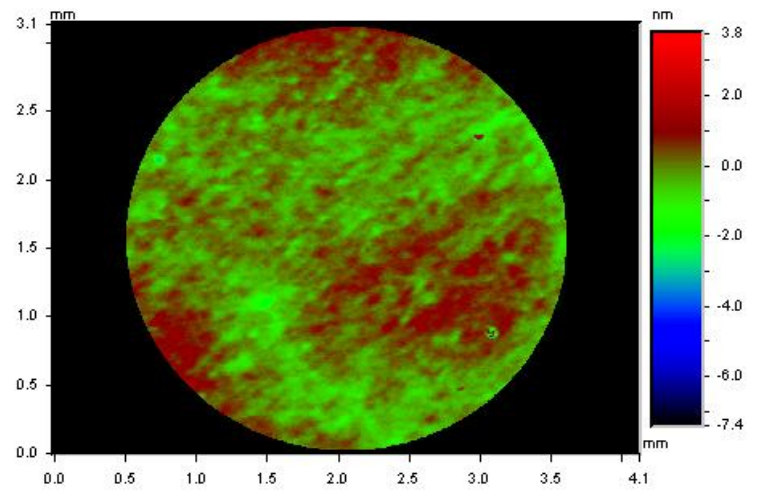

Fig. 5: Surface Profile IAEBD Laser Mirror

The total integrated scattering is related to the amplitudes of scattered irradiance and the total irradiance as follows:

$$
T I S=1-\frac{R_{s}}{R_{t}}
$$

According to Beckmann and Spizzichino's rough-surface light scattering model, the relation between the scattered light and surface roughness is as follows ${ }^{4}$ in the equation (3).

$$
\text { TIS }=1-e\left[-\left(\frac{4 \pi \cdot \operatorname{Cos} \theta_{i} \cdot R_{q}}{\lambda}\right)^{2}\right]
$$

here $\mathrm{R}_{\mathrm{q}}$ is rms roughness of an optical surface, $\theta_{i}$ is angle of incidence, and $\lambda$ denotes wavelength of light.

\section{Table-II: Total Integrated Scattering Values of Bare Substrate, EBD and IAEBD Films}

\begin{tabular}{cclc}
\hline \hline Parameter & $\begin{array}{c}\text { Bare } \\
\text { Substrate }\end{array}$ & $\begin{array}{l}\text { EBD } \\
\text { Mirror }\end{array}$ & $\begin{array}{c}\text { IAEBD } \\
\text { Mirror }\end{array}$ \\
\hline TIS & $4.6 \times 10^{-5}$ & $1.2 \times 10^{-3}$ & $8.3 \times 10^{-5}$
\end{tabular}

IAEBD mirrors have lower scattering values compared to EBD mirrors.

\section{B. Optical Constants of Thin films}

An automated M-2000 VI Spectroscopic Ellipsometer of J A Woollam make, which can measure thin film properties in the range of 370 - $1690 \mathrm{~nm}$ wavelength, is engaged for analysis. Spectroscopic ellipsometry (SE) is a non-destructive method used to determine physical thickness and optical constants of coatings. In ellipsometry, the variation of the amplitude and the phase difference between the perpendicular (p) and the parallel (s) components of the reflected light polarized with respect to the plane of incidence are measured ${ }^{18}$. Mukesh et al fabricated $\mathrm{Ta}_{2} \mathrm{O}_{5}$ films of refractive index of 2.0419 at $550 \mathrm{~nm}$ without assisted ion beam on a heated substrate at $250^{\circ} \mathrm{C}^{19}$. The single layer $\mathrm{SiO}_{2}$ film and the single layer $\mathrm{Ta}_{2} \mathrm{O}_{5}$ film deposited on two separate substrates, by EBD process are evaluated for optical constants with the ellipsometer. Similarly, single layer $\mathrm{SiO}_{2}$ film and the single layer $\mathrm{Ta}_{2} \mathrm{O}_{5}$ films deposited on two separate substrates by IAEBD process are also evaluated. Najwa sidqi et al demonstrated $\mathrm{SiO}_{2}$ films deposited by IAD process from $\mathrm{SiO}_{2}$ source with no oxygen backfill at a deposition rate of $2 \AA / s$ and achieved refractive index between 1.47 and 1.45 in the wavelength range $500-1000 \mathrm{~nm}^{20}$.
Refractive indices and extinction coefficients of $\mathrm{SiO}_{2}$ are plotted in Fig. 6 \& Fig.8. For $\mathrm{Ta}_{2} \mathrm{O}_{5}$ film the optical constants are plotted in Fig.7 \& Fig.9.

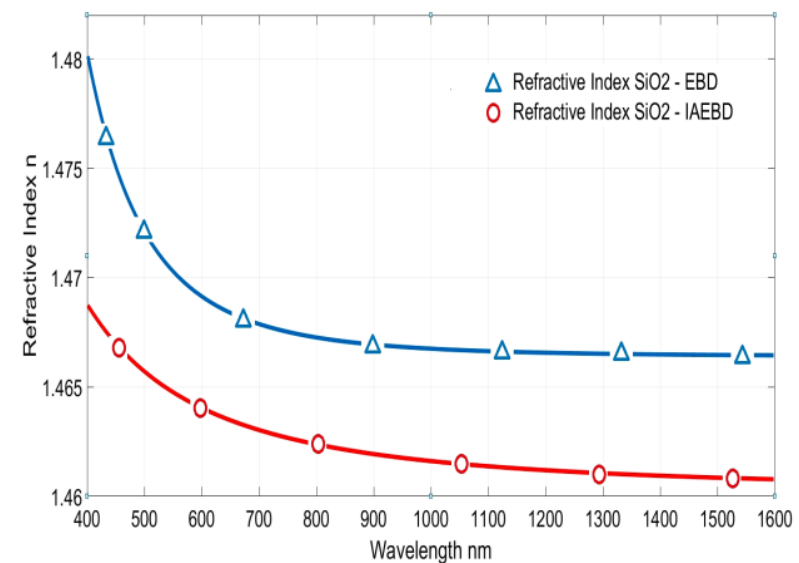

Fig. 6: Refractive indices of $\mathrm{SiO}_{2}$ films with $\mathrm{EB}$ and IAEBD process.

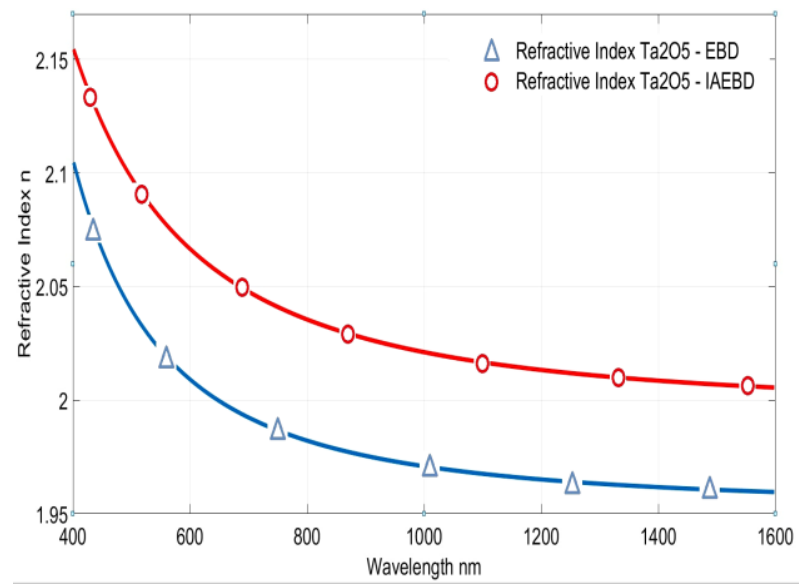

Fig. 7: Refractive indices of $\mathrm{Ta}_{2} \mathrm{O}_{5}$ films with $\mathrm{EB}$ and IAEBD process.

Optical constants of $\mathrm{SiO}_{2}$ and $\mathrm{Ta}_{2} \mathrm{O}_{5}$ are tabulated in Table- III and Table- IV at the wavelength of interests where metrological and High power Laser applications. $\mathrm{SiO}_{2}$ and $\mathrm{Ta}_{2} \mathrm{O}_{5}$ films deposited with assisted Ion beam coating shown zero value of extinction coefficient, purely dielectric in nature and suitable for Laser mirrors.

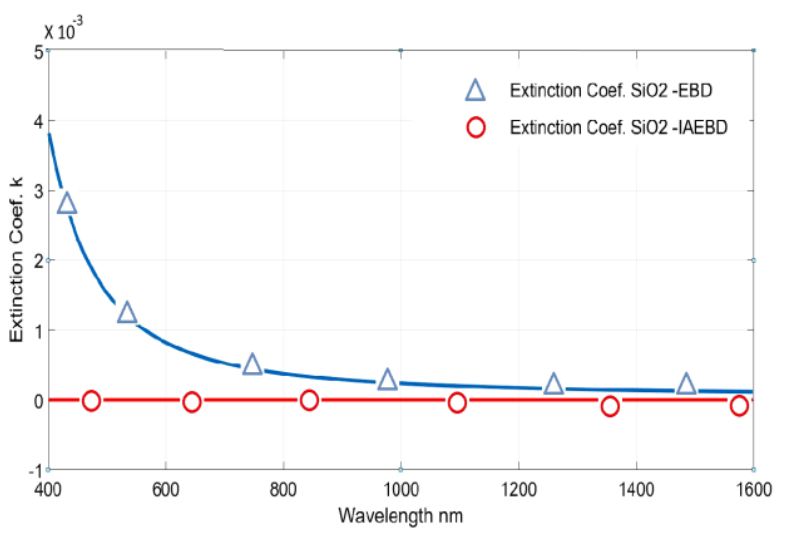

Fig. 8: Extinction Coefficients of $\mathrm{SiO}_{2}$ films with $\mathrm{EB}$ and IAEBD process.

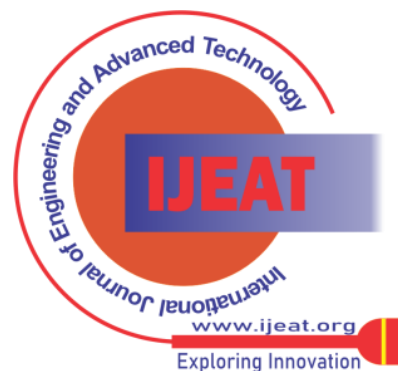


Table-III: Optical Constants of Silicon Dioxide and Tantalum Pentoxide Films with EBD Process

$\mathrm{SiO}_{2}$ Film

$\mathrm{Ta}_{2} \mathrm{O}_{5}$ Film

\begin{tabular}{ccccc}
$\begin{array}{c}\text { Optical } \\
\text { Constant }\end{array}$ & $\begin{array}{c}\text { @ 532 } \\
\mathrm{nm}\end{array}$ & $\begin{array}{c}\text { @ 632.8 } \\
\mathrm{nm}\end{array}$ & $\begin{array}{c}\text { @ 532 } \\
\mathrm{nm}\end{array}$ & $\begin{array}{c}\text { @ 632.8 } \\
\mathrm{nm}\end{array}$ \\
\hline $\mathrm{n}$ & 1.4708 & 1.4686 & 2.0276 & 2.0026 \\
$\mathrm{k}$ & 0.00122 & 0.0007 & 0.0049 & 0.00282
\end{tabular}

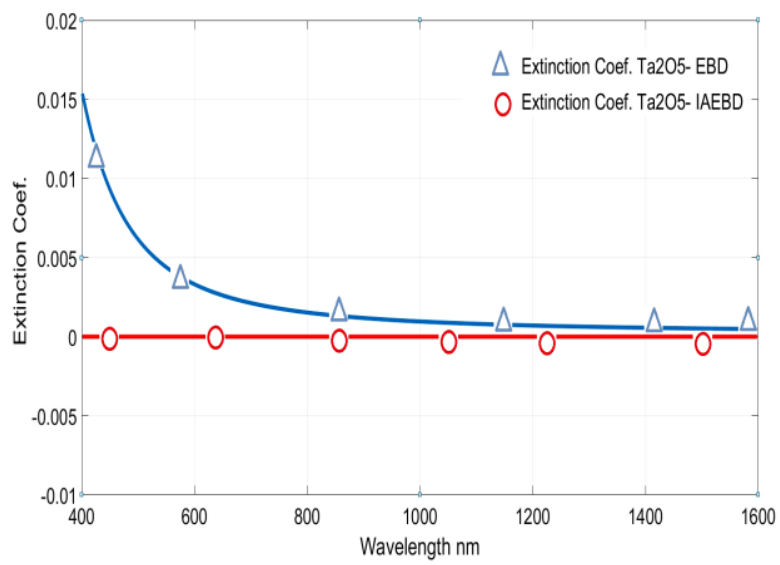

Fig. 9: Extinction Coefficients of $\mathrm{Ta}_{2} \mathrm{O}_{5}$ films with EB and IAEBD process.

Table-IV: Optical Constants of Silicon Dioxide and Tantalum Pentoxide Films with IAEBD Process

\begin{tabular}{ccccc}
\hline \hline & \multicolumn{2}{c}{$\mathbf{S i O}_{2}$ Film } & \multicolumn{2}{c}{$\mathbf{T a}_{2} \mathbf{O}_{5}$ Film } \\
Optical & @ 532 & @ 632.8 & @ 532 & @ 632.8 \\
Constant & $\mathrm{nm}$ & $\mathrm{nm}$ & $\mathrm{nm}$ & $\mathrm{nm}$ \\
\hline $\mathrm{n}$ & 1.4650 & 1.4636 & 2.0858 & 2.0594 \\
$\mathrm{k}$ & 0 & 0 & 0 & 0 \\
\hline \hline
\end{tabular}

C.Reflectivity of EBD and IAEBD Multi Layer Mirrors

Deposited films are measured for reflectivity with Agilent make UV-VIS-NIR Spectrophotometer. The spectrophotometer has capability of measuring reflectivity and transmission of mirrors at variable angle of incidence. The mirrors deposited, in the present work are measured at $45^{\circ}$ angle of incidence and data is plotted in Fig. 10 \& Fig. 11. The EBD films showed a flat band of S- polarization from 530 $\mathrm{nm}$ to $710 \mathrm{~nm}$ with centre wavelength at $620 \mathrm{~nm}$. The flat band width is $180 \mathrm{~nm}$. The IAEBD films, on other hand showed, flat band of S-polarization from 520 to $670 \mathrm{~nm}$ with central wavelength of $595 \mathrm{~nm}$. IAEBD mirrors shown narrow flat band and central wavelength shift towards lower wavelengths. IAEBD films exhibited good control of thickness witnessing of smooth fall in amplitudes of harmonics on either side of the flat band of the reflection curve.

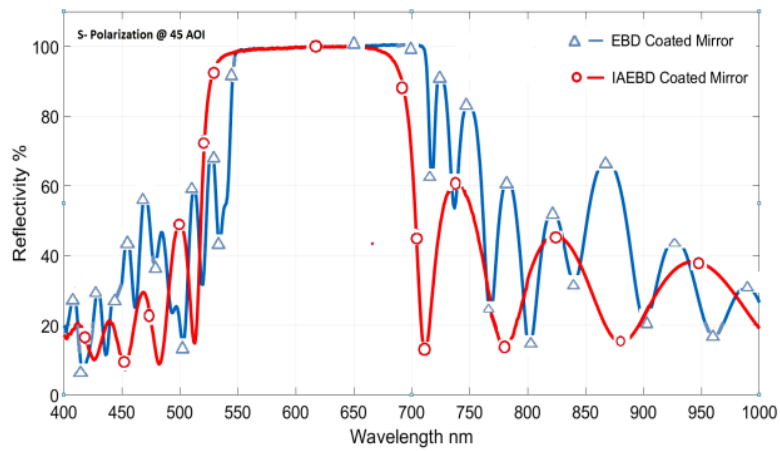

Fig.10. S-Polarization Reflectivity of EB and IAEBD mirrors

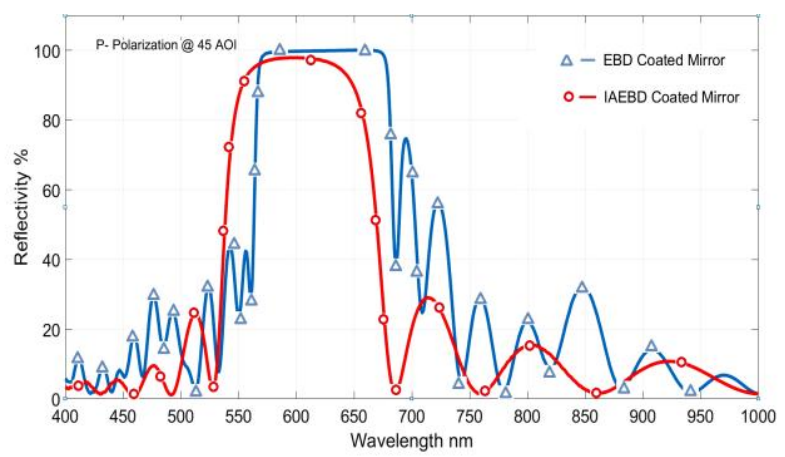

Fig.11. P-Polarization Reflectivity of EB and IAEBD mirrors

D. Cavity Ring Down Loss of EBD and IAEBD Multi Layer Mirrors

Accuracy of the reflectivity of high reflectivity Laser mirrors measured by spectrophotometer is limited to $1 \%$. Cavity ring down loss meter works on the principle of measurement of decay time of the light of the resonator. This technique helps in measuring reflectivity or total loss of very high reflectivity mirrors, where conventional measurement techniques fail. Another advantage of this technique is having immunity towards intensity fluctuations of the Laser source, as the measurement completely relies on the relative change in intensity of the pulse ${ }^{21}$. When the Laser is launched inside the optical cavity, Laser intensity decreases after every round trip. The decrease in intensity is measured with a photodiode by monitoring the light leaking through one of the cavity mirrors. The intensity after a launching time $t$, inside the cavity enclosed by two mirrors of reflectivity $R_{1}$ and $R_{2}$ separated by a distance $d$, is given by ${ }^{21}$

$$
\begin{aligned}
I(t) & =I_{o} \cdot e^{-\frac{t}{\tau}} \\
\text { where } \tau & =-\frac{2 d}{c \cdot \operatorname{Ln}\left(R_{1} \cdot R_{2}\right)}
\end{aligned}
$$

The multi-layer mirror coatings are tested with the loss meter for total loss of the mirror at $635 \mathrm{~nm}$ wavelength. Initially, the loss meter measurements are carried out with reference linear cavity of mirrors $R_{1}$ and $R_{2}$. Laser pulse is

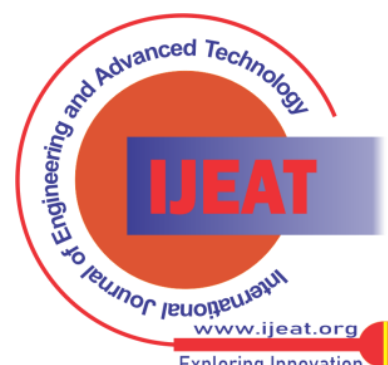


launched in to the cavity from $\mathrm{R}_{1}$ and the leaking beam is monitored from mirror $\mathrm{R}_{2}$. The test mirror $\mathrm{R}$ is introduced in the cavity such that Laser beam from mirror $\mathrm{R}_{1}$ is incident at $45^{\circ}$ angle to the test mirror. The cavity is aligned so that the photons will be making rounds with in the triangular resonator. Schematic of the loss meter experimental set up is shown in Fig. 12.

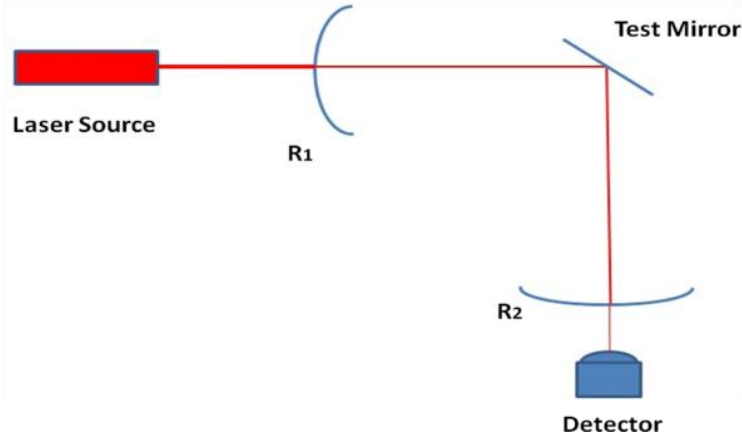

Fig.12. Schematic of Cavity Ring down Loss Measurement Setup

The transmitted light collected from the mirror $\mathrm{R}_{2}$ is plotted with time. The decay time is measured and reflectivity of test mirror is derived. The total loss obtained for IAEBD mirror is $1753 \mathrm{ppm}$, where as for the EBD mirror the loss is $3189 \mathrm{ppm}$. The EBD mirrors shown relatively higher scattering loss due to higher surface roughness and film defects, compared to IAEBD mirrors. The measurements are repeated for three samples in each batch, and a close match of readings is obtained within $20 \mathrm{ppm}$.

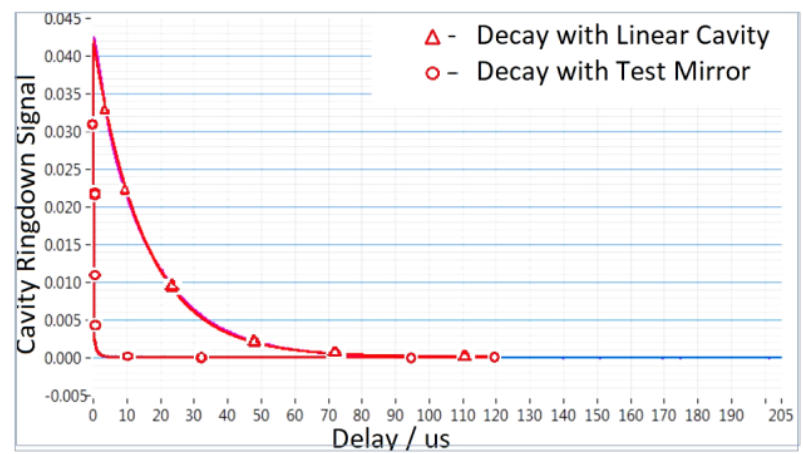

Fig. 13. Cavity Ring Down Decay Time Measurements of EBD Mirror

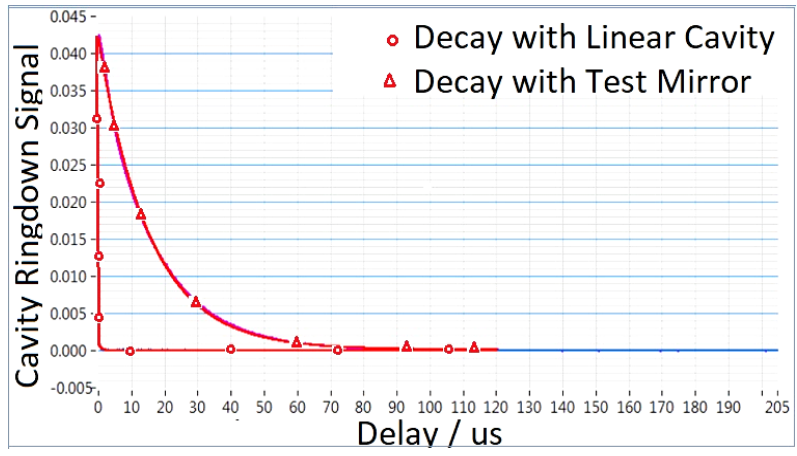

Fig. 14. Cavity Ring Down Decay Time Measurements of IAEBD Mirror

\section{RESULTS AND DISCUSSION}

\section{A. Laser Mirrors with EBD Process}

The multi-layer dielectric Laser mirrors deposited with EB deposition techniques shown a degraded surface roughness compared to the uncoated substrates due to columnar and bubbles structures of the film grown. The single layer $\mathrm{SiO}_{2}$ and single layer $\mathrm{Ta}_{2} \mathrm{O}_{5}$ films exhibited non-zero coefficients of extinction which may lead to absorption of light. The absorption loss is evidenced with more cavity decay loss when measured with cavity ring down loss meter for mirrors realized with EBD process.

\section{B. Laser Mirrors with IAEBD Process}

The films grown with additional ion beam gun during electron beam deposition exhibited surface roughness nearly the same as the roughness prior to coating due to enhanced distribution of the film with assisted ion beam. Near zero extinction coefficients for single layer $\mathrm{SiO}_{2}$ and $\mathrm{Ta}_{2} \mathrm{O}_{5}$ films are achieved by the coating process of maintaining of partial pressure of oxygen gas inside the chamber during deposition. The estimated Total Integrated Scattering values are two orders lower for the mirrors done with assisted ion beam EB coating than simple EB coated mirrors. The cavity loss of mirrors coated with assisted ion beam process is also relatively lower than that of mirrors deposited with Electron beam alone.

\section{SUMMARY AND CONCLUSION}

$\mathrm{Ta}_{2} \mathrm{O}_{5}$ and $\mathrm{SiO}_{2}$ films realized with IAEBD process are dielectric in nature with zero coefficients of extinction, and also with better surface smoothness, which proves that IAEBD process is superior to simple EBD process. The total integrated scattering should be low for a Laser interacting optical surface to avoid lock-in errors of Laser based rotational sensors. The measured reflectivity and optical losses of mirrors realized with IAEBD process are encouraging and suitable to use mirrors for He-Ne Laser Resonator assemblies at $632.8 \mathrm{~nm}$ wavelength.

\section{ACKNOWLEDGEMENT}

I express my indebted gratitude to shri K Rambabu, shri G Krishna Rao, and shri MVYS Ravi Kumar -Senior technologists in RCI, Hyderabad, for extending incessant support and guidance in the work. I thank shri BHVS Narayana Murthy, Distinguished Scientist, who motivated me for the indigenous development work. I also thank Dr. V A Naidu and Mrs. K Radhika for extending help in characterization and compilation of measured data.

\section{REFERENCES}

1. Hyun-Ju Cho, Jae-Cheul Lee, and Sang-Hyun Lee, "Design and development of an ultralow optical loss mirror coating for zerodur Substrate”, Opt. Soc. Korea, vol.16, Mach 2012, pp.80-84.

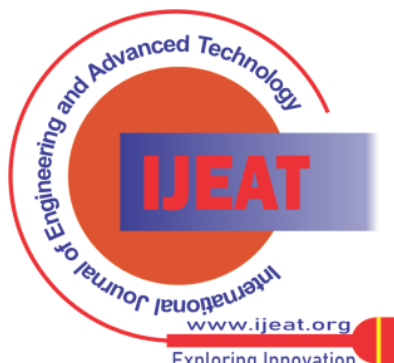


2. Traci R. Jensen, John Warren, and Robert L. Johnson, "Ion-assisted deposition of moisture-stable Hafnium oxide films for ultraviolet applications", Appl. Opt., 41, June 2002, pp.3205-3210.

3. James E. Harvey, Sven Schroder, 'Total integrated scatter from surfaces with arbitrary roughness, correlation widths, and incident angles", Opt. Engg., vol.51(1), February, 2012, pp.3402.

4. Zheng Shenrong, Zhou Jing, Gu Peifu, "Roughness characterization of well-polished surfaces by measurements of light scattering distribution" Optica Applicata, vol. XL, No.2, 2010.

5. R. P. Netterfield, P. J. Martin, C. G. Pacey, and W. G. Sainty, "Ion-assisted deposition of mixed $\mathrm{TiO}_{2}-\mathrm{SiO}_{2}$ films", Appl. Phys. vol.66, April 1989, pp.1805-1809.

6. K S Sreeharsha, "Principles of physical vapor deposition of thin films", $1^{\text {st }}$ ed., UK:Elsevier, 2006, pp.96-98.

7. Krishna Seshan, "Hand book of thin film deposition processes and technologies”, $2^{\text {nd }}$ ed., California: Intel Corporation Santa Clara, 2002, pp.195-220.

H. Malitson, "Interspecimen comparison of the refractive index of fused Silica”, Opt. Soc. Am. Vol.55, October 1965, pp.1205-1209.

8. T. J. Bright, J. I. Watjen, Z. M. Zhang, C. Muratore, A. A. Voevodin, D. I. Koukis, D. B. Tanner and D. J. Arenas. "Infrared optical properties of amorphous and nanocrystalline $\mathrm{Ta}_{2} \mathrm{O}_{5}$ thin films", Appl. Phys., Vol. 114, August 2013, pp.3515.

9. G. A. A1-Jumaily, S. R. Wilson, J. J. McNally, J. R. McNeil, J. M. Bennett, and H. H. Hurt, "Optical scattering and microstructure of gold and platinum coatings", Appl. Opt., 1986, pp. 3631- 3634.

10. Bin Fan, Masahiro Suzuki, and Ken Tang, "Ion-assisted deposition of $\mathrm{TiO}_{2} \mathrm{SiO}_{2}$ multilayers for mass production”, Appl. Opt., vol.45, March 2006, pp.1461-1464.

11. S. P. Kumar, M. Kumar, N. Kumari, V. Karar, and A. L. Sharma, "Ion assisted e-beam deposition of $\mathrm{SiO} 2$ thin films with graded refractive index", Frontiers in Optics / Laser Science, September 2018, JTu3A.24.

12. Marco Alvisi, Giorgio De Nunzio, Massimo Di Giulio, Maria Cristina Ferrara, Maria Rita Perrone, Lucia Protopapa, and Lorenzo Vasanelli, "Deposition of $\mathrm{SiO}_{2}$ films with high laser damage thresholds by ion-assisted electron-beam evaporation", Appl. Opt., vol.38, March 1999, pp. 1237-1243.

13. Jian Leng, Li Zhao, Yiqin Ji, Huasong Liu, and Kewen Zhuang, "Absorption, structural, and electrical properties of Ge films prepared by ion-beam-assisted deposition”, Appl. Opt., vol. 53, No. 4, February 2014.

14. John R. McNeil, Alan C. Barron, S. R. Wilson, "Ion-assisted deposition of optical thin films: low energy vs high energy bombardment", Appl. Opt., vol. 23, February 1984, pp.552-559.

15. Mansour S. Farhan, E. Zalnezhad, A.R. Bushroa, "Properties of $\mathrm{Ta}_{2} \mathrm{O}_{5}$ thin films prepared by ion-assisted deposition", Mat. Res. Bulletin, vol. 48, October 2013, pp. 4206-4209.

16. Daniel Malacara, Manuel Servin, Zacarias Malacara, "Interferogram analysis for optical testing”, $2^{\text {nd }}$ Ed., Taylor and Francis Group: CRC press, 2005.

17. Ji Yi-Qin, Jiang Yu-Gang, Liu Hua-Song Wang, Li-Shuan, Liu Dan-Dan, Jiang Cheng-Hui, Fan Rong-Wei, Chen De-Ying, “Optical constants of $\mathrm{SiO}_{2}$ films deposited on Si substrates", Chin. Phys. Lett. vol. 31, April 2014, 046401.

18. Mukesh kumar, Neelam Kumari, VSRS Praveen Kumar, Vinod Karar, Amit L Sharma, "Determination of optical constants of tantalum oxide thin film deposited by electron beam evaporation", Mat. Today: Proc., vol.5, March 2018, pp. 3764-3769.

19. Najwa Sidqi, Caspar Clark, Gerald S. Buller, Gopala Krishna V. V. Thalluri, Jevgenij Mitrofanov, and Yoann Noblet, "Comparative study of dielectric coatingmaterials for micro-cavity applications”, Opt. Mat. Exp. , vol.9, August 2019, pp.3452-3468.

20. G Sridhar, Sandeep K Agarwalla , Sunita Singh, L M Gantayet, "Cavity ring-down technique for measurement of reflectivity of high reflectivity mirrors with high accuracy” Pramana- J of Phys., vol.75, December 2010, pp.1233-1239.

\section{AUTHORS PROFILE}

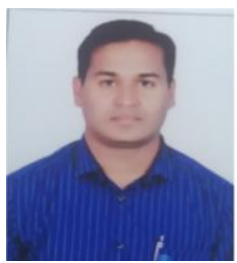

Laxminarayana Gangalakurti, is presently working as scientist in Research Centre Imarat, DRDO, Hyderabad. He did his Masters in Physics with molecular spectroscopy in 2007. He has 4 years of experience in handling vacuum systems for development of thermo-chemical engines. He has done good contribution in design and development

Retrieval Number: 100.1/ijeat.C21530210321

DOI:10.35940/ijeat.C2153.0210321

Journal Website: www.ijeat.org of optical resonators. He has experience in development of Laser based optical sensors, He-Ne Lasers, gas discharge excitation techniques. He developed ultra high vacuum systems and coating systems for special and customized applications. He has experience in handling ion sources, vacuum pumps, vacuum chambers, RGA and mass spectrophotometers, ellipsometry, Optical profilometers, AFM. He has more than 15 years of research experience in optical sensors and thin films technology.

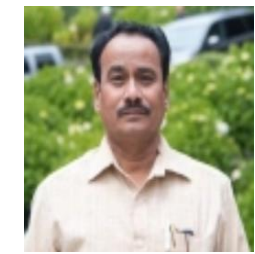

Dr. K Venugopal Reddy, is presently working as Professor in Physics Dept., National Institute of Technology, Warangal, Telangana, India. He joined in Physics Department, REC Warangal as Lecturer in April 1992. In 1997 he was promoted as Senior Lecturer. He became Associate Professor in April 2003. He became Professor and then Head of the department from June 2018. He did his PhD from central university of Hyderabad in field of Material Science under the guidance of Prof. Anil Kumar Bhatnagar. Later continued as CSIR Post Doctoral Fellow in the Field of High Temperature supper conductors in the same lab. His research interests are Condensed matter physics, Materials science, Nano Materials (Composites, Ferrites), Thin Film Technology, Solid State Physics, Instrumentation.

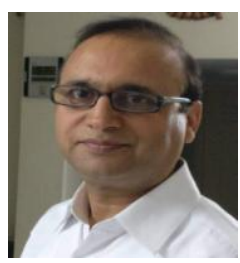

Dr. I M Chhabra, is working as scientist in Research Centre Imarat, DRDO, Hyderabad, Telangana, India. He did MSc. and PhD in Physics. To his credit, he developed electro-optical sensor for critical applications. He developed state of art technologies in the field of optical sensors of national importance. He has developed special adhesives and materials for high $\mathrm{Q}$ mechanical systems. He developed super smooth optical components with nano powder polishing and surface figure correction. He developed He-Ne Lasers and has good command in integration. He has experience in handling, special microscopes, ultra high vacuum systems and devised acceptance test procedures for field testing. He has more than 20 years of research and development experience in optical sensors and associated systems.

Published By:

Blue Eyes Intelligence Engineering and Sciences Publication

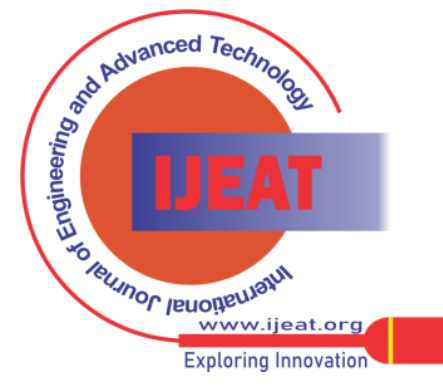

